\title{
Facing the challenge of providing eye care at the National Eye Hospital Colombo during the COVID-19 outbreak in Sri Lanka
}

\section{MP Wijeratne* \& WLLUC Kumaratilake}

National Eye Hospital Colombo, Sri Lanka

"Correspondence: monika.wijeratne@gmail.com

iD https://orcid.org/0000-0003-3816-0862

DOI: https://doi.org/10.4038/jccpsl.v26i5.8327

Received on 9 May 2020

Accepted on 5 June 2020

\section{Summary}

National Eye Hospital Colombo (NEHC) is the apex tertiary eye care institution in the country. This hospital drains about 1500-2000 out-patients per day from all over the island and works round the clock to give maximum service to the nation. The out-patient department and the clinics are running from $7 \mathrm{am}$ to $5 \mathrm{pm}$ attending to all the routine eye problems, meanwhile providing a 24-hour service for the casualty patients daily. The hospital has modern facilities to provide top-most eye care for all and exceed the expectations of those being served. It is crucial to prevent blindness, as eye care interventions dramatically improve the quality of life, thus contributing to incredible economic and social returns. The care provided by this institution extends from simple forms of eye infection to severe degree ophthalmic complications such as retinal and corneal surgeries. Further, NEHC provides a corneal drafting facility through the eye bank. Being a teaching hospital, it also provides opportunities for training various categories of health staff. This report highlights the response of NEHC during the pandemic situation in Sri Lanka.

\section{Public health response and its impact}

Ophthalmology is a high-risk field related to COVID19 due to the need for very close contact during patient care. Moreover, this institution is located at a high-risk area for disease spread. Therefore, safeguarding the hospital staff and patients from COVID-19 has become a real challenge. Providing essential eye care for the patients while assuring the safety of the hospital staff and the community against the spread of COVID-19 was of paramount importance.
A major challenge, the NEHC had to face was the anxiety aroused among the health staff due to uncertainty of several factors related to the behaviour of this new virus such as its pathogenicity, transmissibility, disease severity, prognosis, complications, exposure level, availability and the safety of personnel protective equipment (PPE), etc. The possibility of COVID-19 infected patients presenting with ophthalmologic complications like conjunctivitis and discovery of asymptomatic COVID-19 cases aggravated anxiety among the health staff. Unavailability of PPE especially 
designed for ophthalmic care was a major concern as slit lamp examination requires the eyecare provider to be in very close proximity to the patient. Being the pioneer for eye care in the country, the NEHC has been expected to provide guidance in ophthalmic care for hospitals island wide during this COVID-19 pandemic.

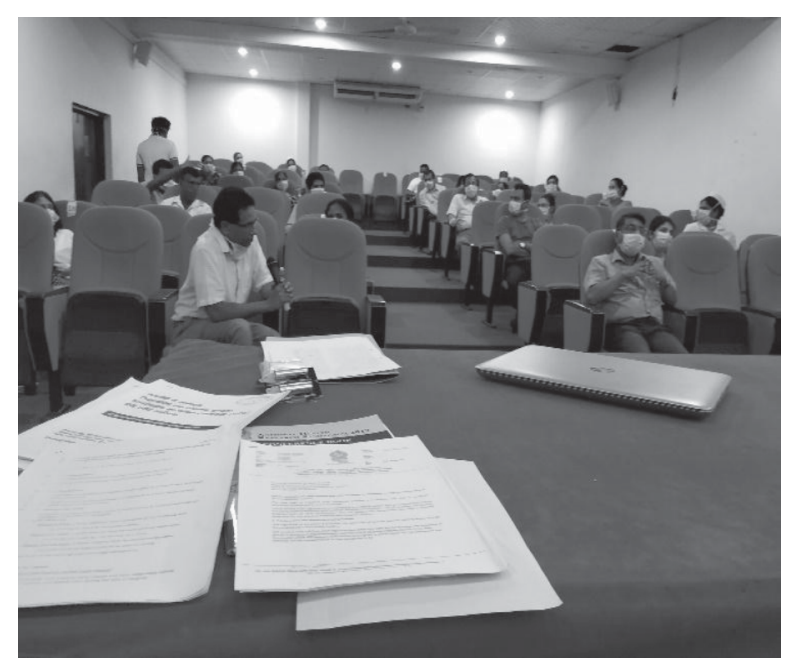

Figure 1: COVID-19 Working Committee meeting

To face these challenges, it was decided to establish a strong body/working committee for decision making and implementing various measures for safe practices of ophthalmology during the COVID-19 outbreak. This working committee, later named as 'COVID-19 Operational Cell' consists of 12 members: director, deputy director, physician, general ophthalmologists, vitreoretinal surgeon, oculoplastic surgeon, microbiologist, anaesthetist, medical officer, special grade nursing officer and infection control nursing officer (Figure 1). All decisions regarding the provision of eye care during this period are being taken by this committee.

The committee holds regular periodic reviews to design and implement tailor made measures for the NEHC at correct timing, switching from one stage to the next, considering all available facts. The committee revisits the measures taken and redesigns them to be more feasible, flexible and safe. Selected measures adopted by the NEHC have been outlined below.
Activity I: Controlling the overcrowding of hospital without compromising ophthalmic care

The NEHC receives around 3000 people per day, which includes the aged and disabled patients with comorbidities, small children, neonates, immunecompromised patients and pregnant mothers who are highly vulnerable for the above infection and may contribute to the spread as well. It is important to prevent patient congestion, unnecessary delay and waiting at the clinics, investigation rooms, operation theatres and at the other facilities provided by the hospital. This includes special investigations, examination for glasses, driving license requirements and many more.

Several measures have been taken to minimize the congestion inside the hospital while providing the necessary care for the patient. At the entrance of the hospital, a banner has been displayed requesting the patients to accompany only one person and to leave the hospital premises as soon as they receive treatment.

Three media conferences were conducted to disseminate the message on restricting the number of individuals visiting the hospital through several electronic media. General public have been encouraged to attend the local eye clinic at the nearest government hospital. A telephone hotline has been introduced (011 3618678) for patients to directly communicate with a senior registrar in ophthalmology to obtain necessary medical advice regarding disease conditions, clinic visits, postsurgical care and continuation of medicine.

Furthermore, the arrangements have been made to provide dedicated telephone connections for all 12 eye units (General Ophthalmology Units-7, Vitreoretinal Surgery units-3, Corneal Unit-1, Oculoplastic Unit-1) allowing patients to communicate with their clinician for the following purposes:

- Requesting appointments or rebooking clinic visits 
- Obtaining dates for surgeries, investigations and other facilities (this greatly reduces the waiting time and unnecessary hospital visits)

- Obtaining immediate medical advice which needs to be followed prior to reaching the hospital in case of an emergency

- Receiving necessary instructions for minor problems and doubts

All above approaches have become the pillars of success in providing essential eye care, while assuring the safety of patients, health staff and the public during COVID-19 outbreak.

Activity II: Preparing an operational guideline for ophthalmic care during the outbreak

An expert panel was appointed to develop an operational guideline for ophthalmic practice during the COVID-19 outbreak. It consisted of two general ophthalmologists, vitreoretinal surgeon, corneal surgeon, oculoplastic surgeon, microbiologist, resident physician and a community physician. The guideline was prepared referring the All India
Ophthalmological Society (AIOS) Operational Guidelines for ophthalmic practice during COVID19 outbreak, guidelines issued by the Ministry of Health Sri Lanka, Epidemiology Unit, College of Microbiologists and World Health Organization (13). The drafted guideline for ophthalmic care at the NEHC was reviewed by all other seven ophthalmologists (who were not involved in the guideline preparation and amendments were made according to their suggestions.

Following the newly developed operational guideline, it has been decided to triage the patients and identify COVID-19 suspected cases. A counter has been opened at the OPD to screen all the patients attending the NEHC for symptoms of COVID-19, any contact or travel history and their residence using a checklist developed by an expert panel referring to the available scientific data. If any cage in the checklist is marked as " $\checkmark$ ", that patient is directed to the isolation room (Room 24) specially designed to examine patients with all the necessary safety precautions. At the isolation room, the patient is assessed by both the consultant ophthalmologist and the physician to decide on the management. A special

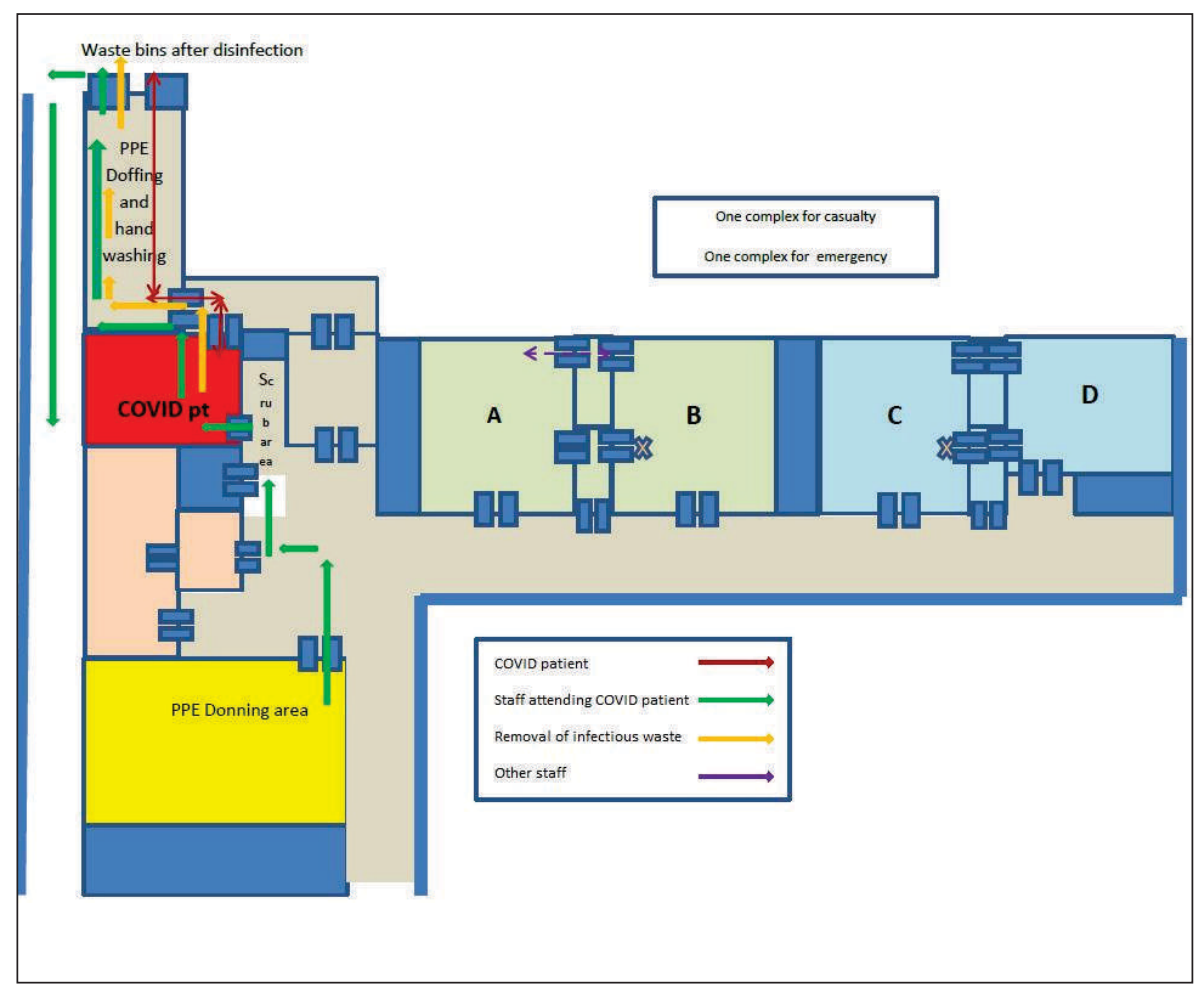

Figure 2: Theatre plan for surgicalprocedures of COVID-19 patients 
ambulance is kept standby enabling quick transfer of the patient to NHSL or IDH if the requirement arises.

Additionally, an isolation ward has been established in the NEHC to admit COVID-19 suspected patients who need ophthalmic care. Isolation ward is managed by the resident physician and consultant ophthalmologist of the relevant unit. A separate set of staff has been allocated for the isolation ward with a special training to care for COVID-19 patients.

Activity III: Introducing a theatre plan for surgical procedure of COVID-19 or suspected patients

A theatre plan has been prepared to conduct surgical procedure for COVID-19 or suspected patients with the support of eye surgeons, microbiologist, anesthetist, special grade nursing officer and the theater in charge sister (Figure 2). This plan ensures the safety of patients undergoing surgical procedure, safety of the theater staff and the equipment.

\section{Activity IV: Preparing institutional guidelines} for rational use of PPE at NEHC

An expert team has been appointed to prepare the guidelines for rational use of PPE in the NEHC. The microbiologist, two infection control nursing officers, special grade nursing officer, resident physician and community physician were involved in preparing tailor-made guidelines for the NEHC use. As specified in the guidelines, depending on the level of risk for each activity, each category of the health staff, is provided with PPE. Steps are being taken to receive an uninterrupted supply of PPE from the Medical Supplies Division, Ministry of Health. However, the unavailability of exclusively designed PPEs for eyecare was a major challenge faced by the NEHC. To address this issue, "breath shields" to cover the slit lamps and "face visors" have been prepared by the hospital staff using locally available material (Figures 3-6). The teamwork of the health staff and support received from donor agencies to provide raw material became our strengths in achieving this target.

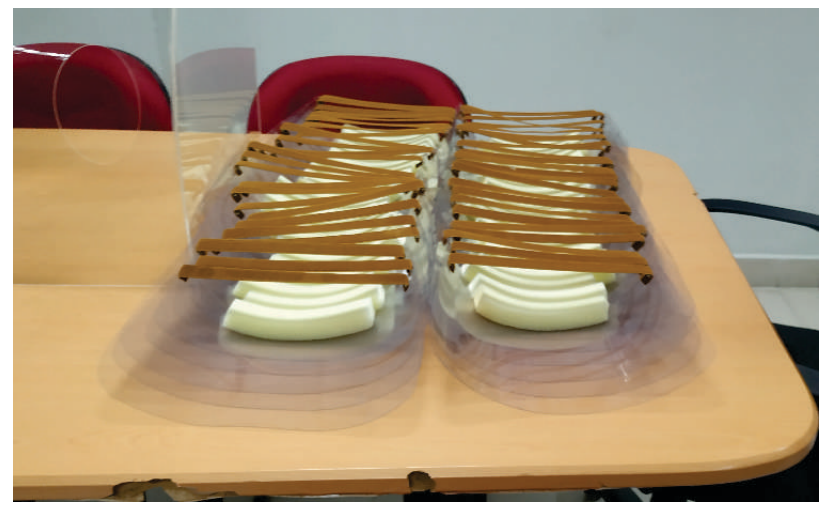

Figure 3: Locally made face visors

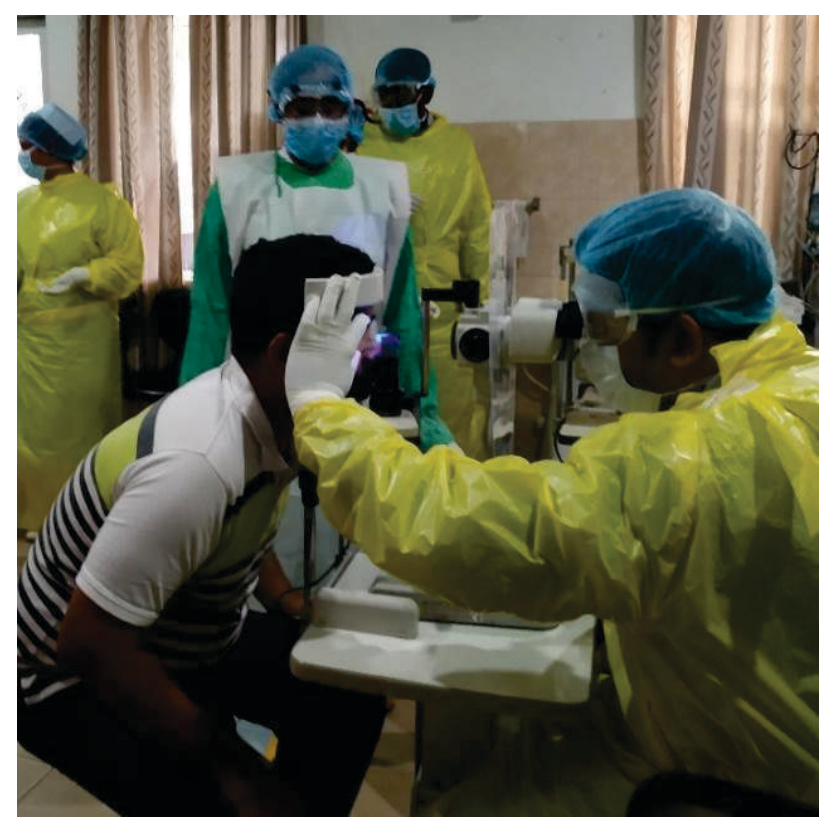

Figure 4: Patient examination - Casualty Room

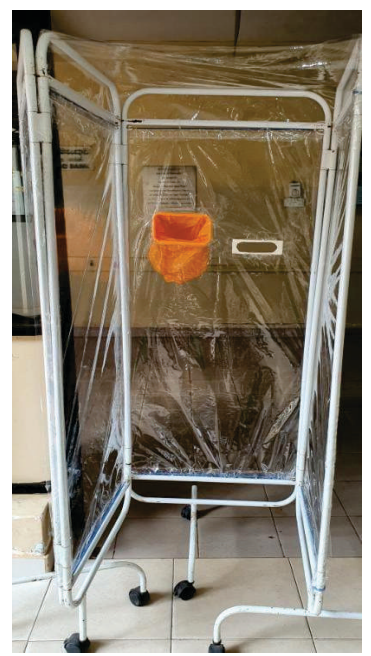

Figure 5:

A locally designed personal protective chamber which can be used for examining patients

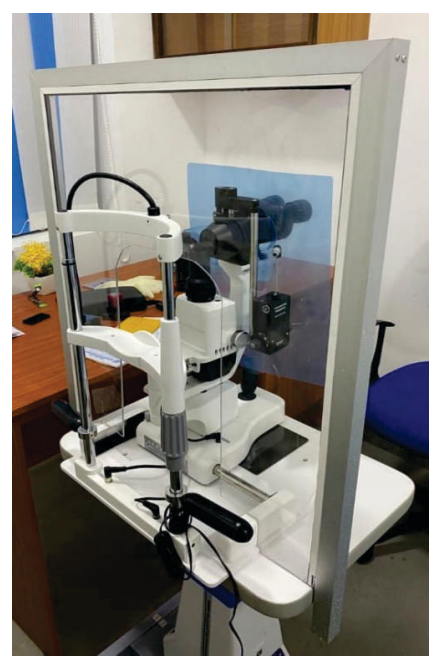

Figure 6:

Slit lampprotected with locally made

'breath shield' 


\section{Activity V: Distribution of medicine for clinic patients}

The NEHC provides long term care through the clinics for many patients who need continuous treatment for certain eye problems like glaucoma. The continuous supply of medicine during this period was identified as a major priority for preventing blindness, which prompted the initiation of medicine distribution among these patients.

Ophthalmologists identify clinic files of their patients who need continuous medical treatment and prescribe the medicine. These prescriptions are handed over to the medicine distribution team led by the deputy director with three pharmacists, one nursing officer (Quality Unit), one IT officer, and one office assistant. Eye drops and oral medicine are carefully packed by the team, double checked, and safely handed over to the Central Postal Exchange to distribute among the patients.

However, sending prescribed medicine referring to the clinic files (passive distribution from patients' perspective) resulted in sending medicine for some patients who are not currently on active treatment,

therefore the medicine distribution process was changed from passive to active, where patients were encouraged to request for medicine so that wastage of resources could be minimized. A media notice is

clinic patients for postal distribution being displayed continuously in electronic channels for patients to request for their medicine through contact number 0112693911.

Initially, the medicine distribution through the post was carried out mainly within Colombo, Kalutara and Gampaha Districts. For the patients who are residing in remote areas, the contact details were extracted from clinic records and prescriptions were sent through social media messages with a covering letter to the director of the nearest hospital, requesting to issue the prescribed medicine. However, it was found that most of the times the prescribed medicine was not available at the local hospital. As a solution, we were able to negotiate with the Central Postal Exchange to distribute medicine in remote areas as well (Figure 7).

Activity VI: Developing an exit plan for NEHC after lifting the curfew

Considering the data published by the National COVID-19 Surveillance System, risk levels in the catchment area of the hospital and referring to the operational guidelines issued by the Ministry of Healthcare and Nutrition, a stepwise approach will be adopted as the exit plan after lifting the curfew (Table 1) (4). This process would require regular periodic reviewing and switching from one stage to the next at precise timing achieved by constant vigilance.

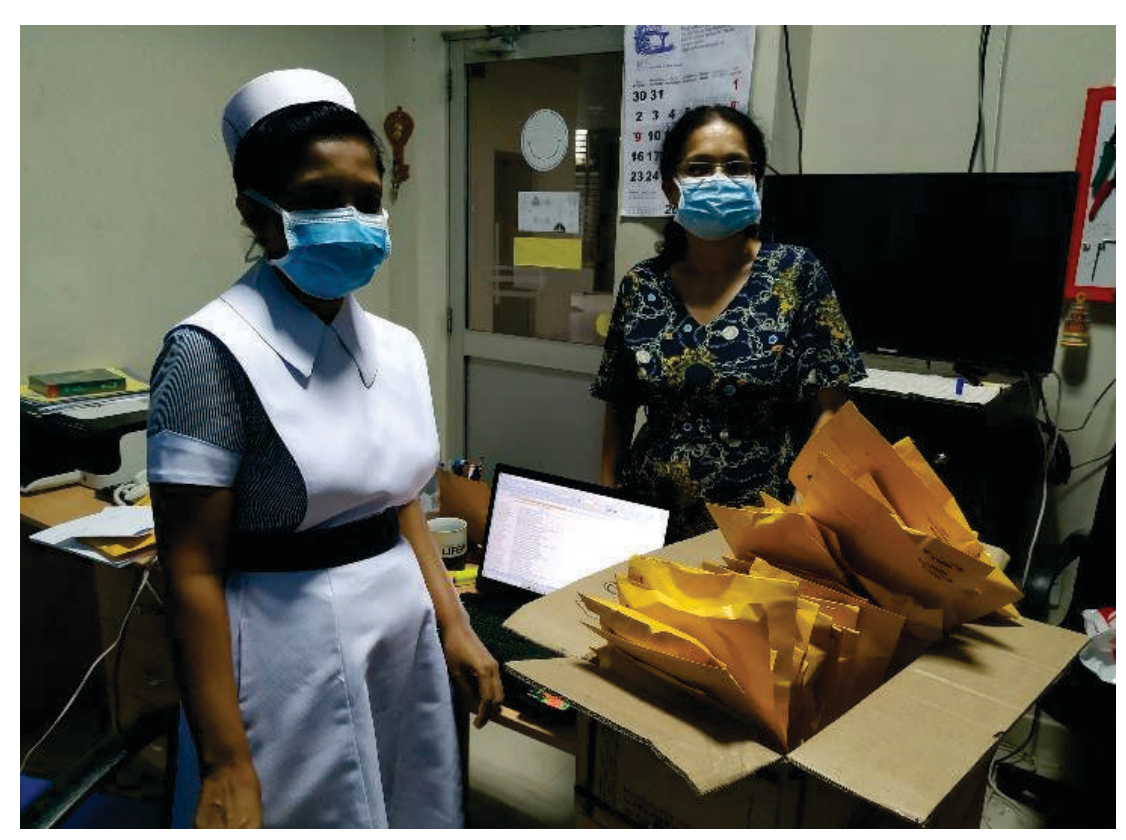

Figure 7: Packing medicines of the 
Table 1: Exit plan for NEHC after lifting the curfew

\begin{tabular}{|c|c|c|c|}
\hline Stage & Period & Target care & Description \\
\hline During curfew & $\begin{array}{l}\text { Throughout the } \\
\text { curfew period }\end{array}$ & Accidents \& Emergencies & Imminent threat for vision or life \\
\hline \multirow[t]{2}{*}{ Early exit stage } & \multirow{2}{*}{$\begin{array}{l}\text { For } 4-6 \text { weeks } \\
\text { after lifting the } \\
\text { curfew }\end{array}$} & Accidents \& Emergencies & Imminent threat for vision or life \\
\hline & & $\begin{array}{l}\text { Patients requiring early } \\
\text { attention }\end{array}$ & $\begin{array}{l}\text { Any patient with vision /life risk if } \\
\text { definitive care delayed for } 1 / 12\end{array}$ \\
\hline \multirow{3}{*}{$\begin{array}{l}\text { Intermediate exit } \\
\text { stage }\end{array}$} & \multirow{3}{*}{$\begin{array}{l}\text { For } 7-11 \text { weeks } \\
\text { after lifting the } \\
\text { curfew }\end{array}$} & Accidents \& Emergencies & Imminent threat for vision or life \\
\hline & & $\begin{array}{l}\text { Patients requiring early } \\
\text { attention }\end{array}$ & $\begin{array}{l}\text { Any patient with vision /life risk if } \\
\text { definitive care delayed for } 1 / 12\end{array}$ \\
\hline & & $\begin{array}{l}\text { Selected proportion of ( } 25- \\
50 \% \text { ) routine clinic } \\
\text { cases/routine surgeries } \\
\text { (proportion will be gradually } \\
\text { increased) }\end{array}$ & $\begin{array}{l}\text { Patients who need comparatively } \\
\text { early interventions (selection) } \\
\text { criteria will be decided upon) }\end{array}$ \\
\hline Final exit stage & \multicolumn{2}{|c|}{$\begin{array}{l}>12 \text { weeks after All patients } \\
\text { lifting the } \\
\text { curfew }\end{array}$} & Routine Eye care will be started. \\
\hline
\end{tabular}

\section{Achievements and the effectiveness of interventions}

1. A guideline for eye care, which can be adopted by other eye care facilities in Sri Lanka has been developed.

2. A guideline for rational use of PPE during eye care has been developed.

3. Dedicated contact lines have been introduced through which patients can request for appointments or rebook clinic visits, obtain dates for surgeries, investigations, and other facilities. Patients can obtain appointments for visits. Minor problems and doubts can be solved over the phone reducing waiting time and unnecessary hospital visits.

4. Distribution of medicine for clinic patients By 30 April 2020, 2256 medicinal packs have been distributed via the post and still the services are rendered under close supervision.

5. Introducing PPEs specially designed for providing eye care (Figures 6-7)

Table highlights the evidence-based practices adopted by NEHC during the COVID-19 outbreak. 
Table 2: Public health principles involved in preventing COVID-19 spread at the NEHC

\section{Public Health Principle}

Minimizing the outbreak risks in high vulnerability settings

Maintaining the social distancing

\section{Measure Taken at the NEHC}

Overcrowding at the NEHC reduced by measures described in activity I, V and VI.

Measures taken to minimize the number of people entering the hospital premises, by reducing waiting time and discouraging unnecessary hospital visits by introducing the concept of telemedicine \& encouraging patients to seek medical care through the dedicated telephone lines before visiting the hospital; and keeping the waiting room as empty as possible, seating has been arranged in a manner that patients should remain at least 2 meters away from each other.

Hand washing facilities provided for everyone who enter the hospital premises; temperature checked using infra-red thermometer at the entrance; patients provided with a surgical face mask when necessary; all the staff members provided with required PPEs as per the guideline; and when entering the hospital, people to walk through a disinfectant area.

Guideline and video clips for proper use of PPEs circulated among all the staff members. Each category of staff members has been demonstrated donning and doffing PPEs. Important messages have been displayed in posters at relevant locations.

Cleaning the floor of high-risk areas with $1 \%$ Sodium Hypochlorite once every 2 hours and moderate risk areas, 3 times a day.

Fogging of the entire hospital is done on a weekly basis

Number of staff members reporting to duty per day has been limited to minimize the risk of exposure.

Triaging the patients entering hospital using a checklist and sending suspected patients to an isolation room for assessment. Arrangements have been made to take the patient for PCR testing if the need arises.

An isolation ward has been established for treating COVID-19 suspected patients who need eye care.

A COVID-19 cell has been established to take technical decisions regarding contact tracing, post exposure risk assessment and quarantining the health staff when need arises. 


\section{Author Declaration}

Acknowledgements: We express our sincere gratitude to the health staff of the NEHC for their unfailing support to face the challenge of providing eye care during COVID-19 outbreak. Succeeding this endeavor could not have been possible without the special support received from consultants Dr Kapila Banduthilake, Dr Kusum Rathnayake, Dr Chameera Bandara, Dr Deepanee Wewalwela, Dr Waruna Gunatilake, Dr Thanuja Ranasinghe and Special Grade Nursing Officer, Ms D Kumarage, \& Public Health Nursing Officer, Ms Nadee Rajakaruna.

Author contributions: Both authors were involved in conception and design of this project and the first author drafted the article and designed the figures. Second author also contributed to the writing of the manuscript, critical revision of the article and final approval of the version to be published.

\section{References}

1. All India Ophthalmological Society (AIOS). Operational Guidelines for Ophthalmic Practice During COVID-19 Outbreak. Government of India. Available from :https:// aios.org/pdf/AIOSOperational-Guidelines-COVID19.pdf. Accessed 10 April 2020.
2. American Academy of Ophthalmology. Returning to ophthalmology practice. Recommendations for urgent and nonurgent patient care. Available from: https://www.aao. org/headline/new-recommendations-urgent-nonurgent-patient-care._Accessed 20 April 2020.

3. Epidemiology Unit. Coronavirus Guideline. Ministry of Health, Sri Lanka. Available from: http://www.epid.gov.lk/web/images/pdf/Circulars/C orona_virus/coronacircular.pdf. _ Accessed 5 April 2020 .

4. World Health Organization. Statement on Transition to a Normal During the COVID-19 Pandemic (2019$n \mathrm{CoV})$. Available from: http://www.euro.who.int/ en/health-topics/ health-emergencies/coronaviruscovid-19/ statements/statement-transition-to-a-newnormal-during-the-covid-19-pandemic-must-beguided-by-public-health-principles. Accessed 18 April 2020.

5. Epidemiology Unit. Coronavirus Disease 2019 (COVID-19). Situation Report 12-03-2020. Available from: http://www.epid.gov.lk/web/ images/pdf/corona\%20virus\%20report/sitrepsl-en12-03\%2010\%20pdf.

6. Ministry of Healthcare \& Indigenous Medical Services, Sri Lanka. Hospital Preparedness for COVID-19. A practical Manual. Available from: https://drive.google.com/file/d/1FD2EZp EZesn MP 4qvcG7DSt2e6W8-USkN/view Accessed 10 April 